International Journal of Biology, Pharmacy and Allied Seiences (IJBPAS) 'A Bridge Betusen Caboratory and QReador'

WwW.iibpas.com

\title{
IOT-BASED CRM BUSINESSES ENHANCE THE ENVIRONMENT FOR DIFFERENT LARGE-SCALE CONSUMERS BASED ON THE INDUSTRY'S MOBILE NETWORKS
}

\section{JEYABHARATHI. ${ }^{1 *}$, SAKTHIMALA.B ${ }^{2}$, DEEPALAKSHMI.G ${ }^{3}$,SURESH KUMAR.K ${ }^{4}$, VINAY RAJ R ${ }^{5}$ AND RENUKA SAGAR ${ }^{6}$}

1: Associate Professor in Computer Science and Engineering at Koneru Lakshmaiah Education Foundation, Greenfields, Vaddeswaram, Guntur, India

2: Assistant Professor in Business Administration at Marudhar Kesari Jain College for Women Vaniyambadi, Tirupattur, Tamilnadu, India

3: Head and Assistant Professor in Business Administration at Marudhar Kesari Jain College for Women Vaniyambadi, Tirupattur, Tamilnadu,India

4: Associate Professor in MBA Department at Panimalar Engineering College, Varadarajapuram,

Nasarathpettai, Poonamallee, Chennai, India

5: Associate Professor (visiting) and Management consultant, Affiliated to Mahatma Gandhi University, Kerala, India

6: Director/ Professor in Business Management, RBVRR Women's College ,Hyderabad, Telangana, India

*Corresponding Author: Jeyabharathi. J; E Mail: shyambharathi2006@gmail.com

Received $20^{\text {th }}$ July 2021; Revised $22^{\text {nd }}$ Aug. 2021; Accepted $30^{\text {th }}$ Sept. 2021; Available online $1^{\text {st }}$ Nov. 2021

https://doi.org/10.31032/IJBPAS/2021/10.11.1042

ABSTRACT

One goal for these research is to examine how quantitative Customer Connection Administration (CRM) affects vendors' knowledge intake. The purpose of this article is to discuss how to employ competition information for individual gain. Owing to the writers, the buyer should comprehend either the maximum dependable suppliers or the right price of their 
knowledge in order to making the greatest of competition espionage. The proper assessment of data may be done by using analysis CRM. CRM businesses have improved salespeople's capabilities (such as heat maps) and collaborated with various large-scale consumer or industry mobile networks (such as big advertising study institutions) to offer a consumer analytical solution.Notwithstanding such, many businesses prefer to depend on basic CRM solutions that essentially enable workers to keeping track of current ratings. Distributing networks could employ this analysis CRM software since it increases salespeople' capacity to comprehend material and apply knowledge to match items to customer demands.

\section{Keywords: Confidence; Quantitative CRM; Data usage; MOA theory; Environment INTRODUCTION}

Research on the role of salespersons in strategic planning is plentiful [1-3]. Initially, the salesperson was a valuable resource for the overall planning of the company.This makes sense since it has proven to provide the company with significant financial and strategic rewards [4]. Gathering quality data can also support the seller in the sense that it permits the seller to better serve the buyer [5]. Despite all the advantages, persuading sellers to gather and use competition manpower has complicated everything. This is considered to be caused by the seller's lack of a noticeable reward [6]. We believe that there are other elements, in addition to motivation, that contributes to a seller's inability to embrace advanced analytics. In specifically, in addition to the absence of desire, there may be a lack of opportunity due to the lack of adequate instruments, which hinders the seller from seeing the short-term benefits of using advanced analytics.

CRM System is a technique for evaluating customer and market records to gain guidance which can be used to optimize strategies [7-8]. In particular, CRM System aids the seller by merging client manpower (e.g. customer attitude info) and statistical data (e.g. Molecular genetics) with the knowledge of competitors acquired by the seller. This synthesizing and interpretation of data sets can be considerably enhanced by artificial intelligence technology and software. The functional and social are different between the CRM system and the primary CRM depth Indistinct, functional CRM is designed to be an administration method of implementing larger-scale, repeatable business functions across the sales team, whereas The goal of community CRM is to understand about it and build consumer 
relationships through the use of data gathered from internet platforms [10]. Although the functional CRM and communal CRM could drive competitive intelligence collection, analytical CRM is more suited for connecting seller-gathered knowledge between different forms of buyer and market smartness. Logical CRM is indeed a platform for merging different kinds of intelligence with competitor analysis obtained by sellers should provide timely insights to sellers to reply smartly in confusing conditions.

\section{Related Works}

It appears improbable that a seller would take data from a source that he or she does not believe and value. The purpose of this study has to be on analytical CRM since that offers sellers besides a tool that they can use to react rapidly based on competitive information gained via buyer-seller communication. A buyer may, as, e.g., inform the seller that it'sa seller's item that offers a unique advantage that is no longer functional upon a competitor's product. It could be crucial strategic intelligence or a bit of information that is pertinent to that customer. If buyer wants are varied, the seller is confused if this data should be used. Analytical CRM may quickly run models for evaluating the quality of the data and will it be useful in securing further clients.
Overall, as previously stated, the research provides both practical and theoretical through demonstrating how a seller's utilization of logical CRM supports the details use behavior. It is done mostly by increasing the seller's ability to value such data. We use the motivation, chance, and capability (MOA) concept as a theoretical approach for why this happens. Moreover, we propose an information value index as just a methodological involvement.

CRM serves an essential role and eliminating some of these factors will affect attitudes [11-12]. According to previous research, sellers did not enter all of their data into CRM systems because they did not get that benefit while doing so rather than storing it all in their minds or writing instructions [13]. This lack of desire might well have vanished, as evidence now exists that sellers can use CRM systems to act on competition knowledge and achieve greater effectiveness in a pain-free manner [14]. A further impediment to employing advanced analytics is that sellers must deal with an everincreasing volume of data. Firms and their sellers are confronted with an increasing volume of buyer and trade data. Because of their limited computational capacities, sellers may experience an overload of information as a consequence of this onslaught of data, in 
which they seek to digest a level of data that surpasses their capacity to ingest otherwise comprehend in a specific period [15]. This may limit a seller's ability to change his or her behavior to take advantage of strategic planning.

The value of data is a key factor in determining whether seller strategy development is used. [16] Takes a commercial approach to content value, claiming that the data are only meaningful if it immediately improves profits, lowers costs, or is promoted. Take a broader view of respective value in [17], which defines it as the extent to which data can be utilized. The ability of a seller to identify the quality of data distinguishes him or them as a person who is more than a taker of orders, permitting the seller to go along with the knowledge it will help and improve his or her potential and create long-term connections with buyers. To be a more interactive seller, a salesperson must be able to assess the quality of data to both the customer and his or her own company [18], otherwise valuable information will be censored or omitted [19]. Advanced analytics among sellers may be related to the improved data concept ensures if it is used [20]. Is defined as "the ability of the seller to relate as opposed to competing options, the product/service being provided to consumers' suits their requirements. Sales representatives should be able to demonstrate the ability to modify a marketing plan for each customer and situation [21]. This enables the seller to use contentious info it creates instantaneous decisions about where to best oppose strategic objectives and meet the needs of clients who may be continually evolving. [22], who views sellers as information brokers whose performance is contingent based on their abilities to leverage present information, emphasizes the relevance of this. This shows that sellers are less likely to be successful if they do not use competitor knowledge in their own sales pitches. Figure 1 depicts the structural framework that we will put to the test in this study. We believe that logical CRM has a direct positive association with detailed user attitudes, as evidenced by our findings. Furthermore, we believe that the connection between logical CRM and data use habits will be mediated by trust and the right type of information. 


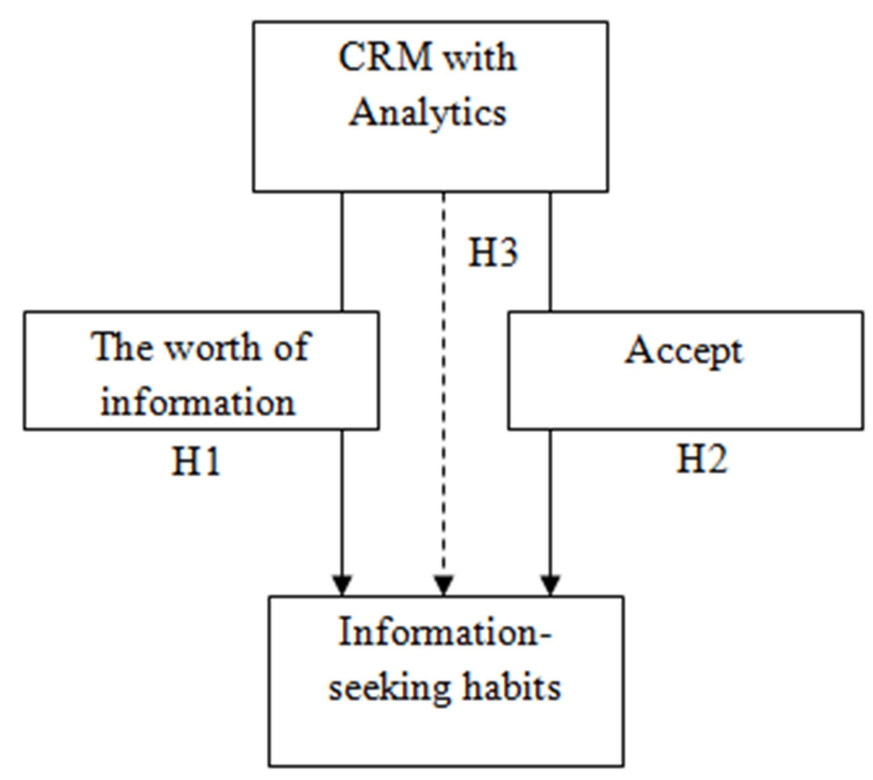

Figure 1: Use of Competitive Intelligence by Salespeople

\section{RESULTS AND DISCUSSIONS}

The dependent variables in our conceptual model were subjected to confirmatory factor analysis (CFA). This contained 10 factors for information users ' attitude, confidence, and the right type of information. Because the third data use habit item had a uniform loading below the $|0.5|$ criteria, it was eliminated from the final analysis, leaving 9 items. For a three-factor framework, the estimation model demonstrated a satisfactory fit and provided testimony of convergent validity.: $a_{1}=92.05$, $\mathrm{df}=34, \mathrm{CFI}=1.97, \mathrm{RMSEA}=1.12, \mathrm{SRMR}$ $=1.03$. This was matched the two methods: $\mathrm{a}_{2}=439.49, \mathrm{DF}=37, \mathrm{CFI}=1.83, \mathrm{RMSEA}=$ $1.29, \mathrm{SRMR}=1.09$ a unique framework with all latent variables put on the same factor: $\mathrm{a}_{2}$ $=255.36, \mathrm{DF}=39, \mathrm{CFI}=1.82, \mathrm{RMSEA}=$ $1.25, \operatorname{SRMR}=1.19$. The AVE values for information marketing products $(0.70)$, trust (0.93), and content categories (1.09) were greater than standard squared correlation estimates, showing construct validity, and were greater than the $|0.5|$ thresholds, indicating convergent validity. The build composite reliability ranged from 0.82 to 0.98 , which is higher than the acceptable threshold of 0.60 . The findings of the analysis, taken collectively, imply that the measurements are reliable and valid. For statistical analysis and relationships, see Table 1. 
Table 1: Statistical descriptions and correlations

\begin{tabular}{|c|c|c|c|c|c|c|}
\hline Variant & Mean & $\begin{array}{c}\text { Standard } \\
\text { Deviation }\end{array}$ & $\mathrm{A}$ & $\mathrm{B}$ & $\mathrm{C}$ & $\mathrm{D}$ \\
\hline CRM with Analytics & $\mathrm{X}$ & $\mathrm{X}$ & $\mathrm{X}$ & & & \\
\hline The worth of information & $\mathbf{2 . 7 0}$ & $\mathbf{2 . 3 3}$ & $\mathbf{0 . 1 2}$ & $\mathbf{0 . 3 5}$ & & \\
\hline Accept & 2.72 & 2.35 & $\mathbf{0 . 0 8}$ & $\mathbf{0 . 3 8}$ & $\mathbf{0 . 4 9}$ & \\
\hline Information-seeking habits & 2.56 & $\mathbf{2 . 3 9}$ & $\mathbf{0 . 2 5}$ & $\mathbf{0 . 4 9}$ & $\mathbf{0 . 4 9}$ & $\mathbf{0 . 4 2}$ \\
\hline
\end{tabular}

Researchers utilized Modeling Approach 4 to assess a similar multiple mediation framework with 10,000 bootstrapped variables as well as a 95 percent bias-corrected confidence level. A goal of this research is to see how a sophisticated CRM system affected data use habits, as moderated through both information value and trust. We can test every one of the three principles in one single component using this method. The findings of the study indicate that a sophisticated CRM system may contribute to higher information use habits, with information sources moderating this impact slightly. This might mean that, while using analytical CRM has no bearing on whether or not the supply of competitive intelligence is respected, it does affect whether or not the seller adjusts his or her actions about the competitive intelligence. These observed associations exist independent of the seller's sexuality or amount of expertise.

To get the most out of competitive intelligence, the seller needs to learn how to value situations properly. New progress in
CRM systems has enhanced this system integrates many streams of real-time competition knowledge. It will make it much easier for sellers to digest big amounts of competitor knowledge and feel secure about adopting that into their marketing strategy.

Furthermore, competitive intelligence must be used quickly, and sellers are frequently unable to efficiently digest and apply the data they gather. Significant research has started in this field to identify the conditions under which sellers are much more likely to use the intelligence which they gather.Despite these theoretical gains,some motivated sellers would not use CRM systems to help them study and then use competitive intelligence continuously since they see CRM systems as a string rather than a beneficial service.This necessitates a description of how a CRM system may be used to inspire sellers and allow them to use competitive intelligence more deftly.

\section{Management actions :-}

Sales representatives must use the competitive intelligence that getsbetter their performance. Salespeople, this was thought, 
did not exploit such data due to the lack of drive. This could be argued that the lack of an efficient technique to incorporate various sources (e.g., sales associate data, historical information, customer feedback, and details of other sales representatives in the company) is the principal impediment to sales representatives using competitive manpower to help the selling interplay in the short term. Such barrier has been overcome thanks to a modern intelligent CRM and user experience, the technology currently on the market, which enable salespeople to assess and apply intelligence in previously unheardof ways. This technology isn't used by all sales companies. Sales representatives must guarantee that logical CRM applications are accessible to the whole workforce and that the workforce has received the appropriate practice using this type of platform. Buying that software isn't enough to ensure their use and worth.

At professional conferences and private case analyses, selling firms could also realize the advantages of employing analytical CRM by offering instances of sellers who have successfully used its method to reach targets and progress on other key personal targets. Rather than trying to push the usage of analytical CRM on any sellers who do not recognize its intrinsic worth, this can assist inspire them. This participation is predicted to yield better results.

As a result, business-to-business sales managers must take two steps. To begin, the administration must thoroughly assess several CRM systems and choose one of the best that meets the company's requirements. Whenever the customer's requirements are sophisticated and there isgreater customer diversity in B2B sales, a solution that blends the competitive data gathered by the seller with buyers and business intelligence is commonly used. Several cloud-based analytical CRM software falls under this category. This solution also should employ artificial intelligence to lower the seller's work and time required. Following that, analytical CRM instruction must be methodical. This proposal's collective goal must be stated, as well as the potential advantages to the seller. Sales representatives can practiceutilizing the analytical CRM software using their preferred device for business. The administration then can leverage positive stories from using the technology in contact with the sales force to emphasize the product's benefits, and then choose to provide opportunities for early adoption.

Conclusions and Future Study :- 
Initially, participants are less engaged in the role-playing process than they would be if they were using CRM. Furthermore, even as the narrative approach is crucial for building internal consistency, it does not show outward accuracy. As a result, these situations are designed to as nearly resemble reality is possible to minimize these concerns; nonetheless, future research could observe and report realistic CRM and informational usage behavior Moreover, the need for a student survey in scale validation reduces the pretest's universal applicability. In this main study, they tried to circumvent this restriction by rigorously evaluating a measure using a representative sample. The study also discovered that while servable does not moderate the association between advanced CRM usage \& data consumer behavior, but may have a positive relationship with it. Research should focus on determining if analytical CRM improvements can be used to support sales representatives in determining whether or not they must comfort the set of fiercemanpower, and whether there are the mediating variable factors that enhance or detract from the effectiveness of accepting the form of fierce intelligence. While we concentrated on logical CRM for its capacity to link salespeople's fierce knowledge of consumer and market intelligence, the future study must look at whether community CRM and operational CRM may be utilized to supplement the process. Moreover, due to evolutionary sense, this study focused on data use behaviors also as predictor variables; nevertheless, future research should look at how advanced CRM influences a seller's financial results.

\section{REFERENCES :-}

[1] Kalra, A., Agnihotri, R. and Briggs, E., 2021. The Role of Frontline Employees' Competitive Intelligence and Intraorganizational Social Capital in Driving Customer Outcomes. Journal of Service Research, 24(2), pp.269-283.

[2] de las Heras-Rosas, C. and Herrera, J., 2021. Innovation and Competitive Intelligence in Business. A Bibliometric Analysis. International Journal of Financial Studies, 9(2), p.31.

[3] Sudarti, K. and Fachrunnisa, O., 2021. Religious personal value towards knowledge conversion process: the power of collaboration between sales team. International Journal of Knowledge Management Studies, 12(2), pp.136-160.

[4] Dr.P.Sivakumar, "Analytical framework to build predictive and optimization function from manufacturing industry sensor data using cross-sectional sharing", Big Data,2021 (SCI) 
[5] Dr.P.Sivakumar, "Improved Resource management and utilization based on a fog-cloud computing system with IoT incorporated with Classifier systems", Microprocessors and Microsystems, Jan 2021 (SCI).

[6] Ranjeeth, S., Latchoumi, T. P., \& Paul, P. V. (2020). Role of gender on academic performance based on different parameters: Data from secondary school education. Data in brief, 29, 105257.

[7] Venkata Pavan, M., Karnan, B., \&Latchoumi, T. P. (2021). PLA-Cu reinforced composite filament: Preparation and flexural property printed at different machining conditions. Advanced Composite Materials, https://doi. org/10.1080/09243046.2021, 1918608.

[8] Hayes, A.F., 2017. Introduction to mediation, moderation, and conditional process analysis: A regression-based approach. Guilford publications.

[9] Apaolaza, V., Hartmann, P., D'Souza, C. and López, C.M., 2018. Eat organic-Feel good? The relationship between organic food consumption, health concern and subjective wellbeing. Food quality and preference, 63, pp.51-62.

[10] Wedel, M. and Dong, C., 2020. BANOVA: Bayesian analysis of experiments in consumer psychology. Journal of Consumer Psychology, 30(1), pp.3-23.
[11] Hartmann, P., Fernández, P., Apaolaza, V. and D'Souza, C., 2018. Emotional Claims in CSR Tweets: The Moderating Role of CSR Message Fit. In Advances in Advertising Research $I X$ (pp. 231-242). Springer Gabler, Wiesbaden.

[12] Kucharska, W., 2020. Employee commitment matters for CSR practice, reputation and corporate brand performance-European

model. Sustainability, 12(3), p.940.

[13] Martinez Soto, L., 2017. Spiritual leadership and organizational knowledge processes: New relations in the field of knowledge management. Journal of Applied Christian Leadership, 11(2), pp.26-51.

[14] Labunska, S., Karaszewski, R., Prokopishyna, O. and Iermachenko, I., 2019. Cognitive analytical tools for cost management of innovation activity. Problems and perspectives in management, (17, Iss. 1), pp.395-407.

[15] Mills, A.J., Berthon, P.R. and Pitt, C., 2020. Agile authorship: Evolving models of innovation for informationintensive offerings. Journal of Business Research, 110, pp.577-583.

[16] Pitt, L., Ferguson, S.L. and Berthon, P., 2018. The transition from products to connected health: observations and avenues for future research. AMS Review, 8(3), pp. 233-239. 
[17] Roy, S. and Satpathy, B., 2019. Strategic alliance between information intensive services and supply chain integration: impact on firm performance. Brazilian Journal of Operations \& Production Management, 16(2), pp. 241-260.

[18] Itani, O.S., Agnihotri, R. and Dingus, R., 2017. Social media use in B2b sales and its impact on competitive intelligence collection and adaptive selling: Examining the role of learning orientation as an enabler. Industrial Marketing Management, 66, pp. 64-79.

[19] Anaza, N.A. and Nowlin, E.L., 2017. What's mine is mine: A study of salesperson knowledge withholding \& hoarding behavior. Industrial Marketing Management, 64, pp. 14-24.

[20] Almohaimmeed, B., 2021. The impact of analytical CRM on strategic CRM, operational CRM and customer satisfaction: Empirical study on commercial banks. Uncertain Supply Chain Management, 9(3), pp. 711-718.

[21] AYDIN, S. and Akyollu, S., 2021. The Effects OfCrm Over Salespersons'selling Intention And Sales Performance: A Research In Turkish Non-Life Insurance Market. Uluslararasiİktisadiveİdariİnce lemelerDergisi, (30), pp.291-308.

[22] Gončarovs, P. and Grabis, J., 2017, September. Using data analytics for continuous improvement of CRM processes: case of financial institution. In European Conference on Advances in Databases and Information Systems (pp. 313-323). Springe, Cham. 